\title{
UP4DREAM CAPACITY BUILDING PROJECT: UAS BASED MAPPING IN DEVELOPING COUNTRIES
}

\author{
A. Calantropio ${ }^{1}$, F. Chiabrando ${ }^{1}$, J. Comino ${ }^{1}$, A. M. Lingua ${ }^{2}$, P. F. Maschio ${ }^{2, *}$, T. Juskauskas ${ }^{3}$
}

${ }^{1}$ Laboratory of Geomatics for Cultural Heritage (LabG4CH), Department of Architecture and Design (DAD), Polytechnic University of Turin, Viale Pier Andrea Mattioli, 39, 10125 Torino (TO), Italy - (alessio.calantropio, filiberto.chiabrando, jessica.comino)@polito.it

${ }^{2}$ Laboratory of Photogrammetry, Geomatics, and GIS, Department of Environment, Land and Infrastructure Engineering, Polytechnic University of Turin, Corso Duca degli Abruzzi, 24, 10129 Torino (TO), Italy - (andrea.lingua, paolo.maschio)@polito.it ${ }^{3}$ UNICEF Supply Division, Copenhagen - tjuskauskas@unicef.org

\section{Commission V, WG V/7}

KEY WORDS: Education and Capacity Building, Developing Countries, UAV Photogrammetry, International Cooperation

\begin{abstract}
:
UP4DREAM (UAV Photogrammetry for Developing Resilience and Educational Activities in Malawi) is a cooperative project cofounded by ISPRS between the Polytechnic University of Turin and the United Nations Children Fund (UNICEF) Malawi, with the support of two local Universities (Lilongwe University of Agriculture and Natural Resources, and Mzuzu University), and Agisoft LLC (for the use of their photogrammetry and computer vision software suite). Malawi is a flood-prone landlocked country constantly facing natural and health challenges, which prevent the country's sustainable socio-economic development. Frequent naturals shocks leave vulnerable communities food insecure. Moreover, Malawi suffers from high rates of HIV, as well as it has endemic malaria. The UP4DREAM project focuses on one of the drone project's critical priorities in Malawi (Imagery). It aims to start a capacity-building initiative in line with other mapping missions in developing countries, focusing on the realization and management of large-scale cartography (using GIS - Geographic Information Systems) and on the generation of 3D products based on the UAV-acquired data. The principal aim of UP4DREAM is to ensure that local institutions, universities, researchers, service companies, and manufacturers operating in the humanitarian drone corridor, established by UNICEF in 2017, will have the proper knowledge and understanding of the photogrammetry and spatial information best practices, to perform large-scale aerial data acquisition, processing, share and manage in the most efficient, cost-effective and scientifically rigorous way.
\end{abstract}

\section{INTRODUCTION}

UAVs have proven to be valuable tools in gathering detailed, hard-to-access aerial data, which can then be integrated into the prediction of natural disasters for making detailed emergency preparedness plans, flood modeling, identify potential hotspots for disease outbreaks, evaluate crop health and yields, and others (Boccardo, et al., 2015; Bravo \& Leiras, 2015). While several developmental organizations are trialing drone technologies, some are already scaling up drone employment in the humanitarian context (Triche, et al., 2020), especially in developing countries (Lalrochunga, et al., 2020; Mugala, et al., 2020).

The high potential of UASs (Uncrewed Aerial Systems, also called UAVs - Uncrewed Aerial Vehicles) implementation into emergency mapping, preparedness, and response has been widely tested and identified as a proactive, quick, and efficient technology to be adopted to locate hazards before they become disasters (UNICEF Kazakhstan, 2019). UAVs have been used not only for mapping purposes in these contexts (Bonte-Grapentin, et al., 2017), as international organizations' global response efforts have been carried through drones in vaccine delivery in different world areas (Strickland, 2018). UASs imagery has been assessed in remote contexts (Meier, 2018) by introducing local knowledge hub networks for training UAV pilots ${ }^{1}$ promoted by NGOs partnering with local universities.
The strength of such initiatives of risk reduction often resides in capacity-building approaches that aim to provide local communities the proper knowledge and tools without permanently relying on foreign resources (Back to the Future: Drones in Humanitarian Action - WeRobotics Blog, 2019; BonteGrapentin et al., 2017). Local expertise is, in fact, essential when dealing with fragile territories; local professionals' immediate intervention can boost the event response time, meaning in a prompt localization of the event, that can turn as more effective through a faster assessment of the damage, lives, and resources saving. Moreover, the consulting of the established local capacity and the community knowledge of the area guarantee the acquisition of a complete set of aerial imagery, useful not only for the recovery but also for the reconstruction phases, which usually lack this fast and extensive support.

\section{THE UP4DREAM CAPACITY BUILDING INITIATIVE}

Several large-scale mapping projects in developing countries have been undertaken in the past (Koeva, et al., 2018), such as the Zanzibar Mapping Initiative ${ }^{2}$, whose aim is to provide a complementary set of data to the already existing satellite imagery dataset, currently available on OpenStreetMap. This project inspired UP4DREAM (UAV Photogrammetry for

\footnotetext{
* Corresponding author

${ }^{1}$ https://flyinglabs.org/

${ }^{2}$ http://www.zanzibarmapping.org/
} 
Developing Resilience and Educational Activities in Malawi) ${ }^{3}$, an ISPRS funded Educational and Capacity-Building project that responds to multiple issues relating the emergency mapping, along with the delivery of essential equipment, such as vaccines, and the empowerment of the local community through the implementation of UAS imagery training.

The first part of the UP4DREAM project developed a training session tailored for the ADDA's students (The African Drone and Data Academy ${ }^{4}$ ). As part of the capacity building exercise, Polytechnic University of Turin hosted a seminar on the use of digital photogrammetry software for drone imagery processing, setting up of GCPs (ground control points) to enhance the accuracy levels of the acquired drone imagery, as well as support ADDA with the structural development of their academic curricula, especially around drone imagery acquisition and processing. Another capacity-building workshop has been organized with governmental stakeholders and public institutions on the importance of geospatial data for decision-making in emergencies. A part of the project activities has been focusing on testing data acquisition inside a dedicated drone corridor, established by UNICEF Malawi in $2017^{5}$ for allowing private entities, organizations, and academia to test their drone technology and provide developmental solutions in the Malawi context. The tests were performed during a two-day exercise in the Nsanje district, a flood-prone area in the south of the country, heavily affected by flooding in 2019. The acquisition of large amounts of aerial data, suitable for post-processing with photogrammetry software, can be used to analyze various applications that include flood modeling, mosquito breeding site identification (Hardy, et al., 2017), watershed monitoring, and similar.

\subsection{Framework and aims of the project}

Disaster preparedness and early warning systems are critical to ensure that affected and vulnerable communities get all the necessary support and commodities promptly, without big delays. Currently, early warning systems and disaster preparedness practices in Malawi are developing; however, much of the evidence used to make informed decisions is scattered, not optimized, and not even hosted on Geographic Information Systems (GIS). This makes the preparedness process complicated and inconsistent, leading to vulnerable communities not getting necessary humanitarian help.

The UP4DREAM project aims at developing capacity-building strategies and tools in the field of UAV photogrammetry data acquisition, processing, and analysis, to ensure that the partners will receive an active and constant education and training, on-site and remotely; the Lilongwe University of Agriculture and Natural Resources and the Mzuzu University have been involved in the project, to benefit from the scientific expertise and technical capacities of the Polytechnic University of Turin, and the long-term collaboration with UNICEF through the operational and technical support of its structures and staff. UP4DREAM has been designed as a pilot study that, if fully embraced by the local Government and programmatically applied, can scale through various high-profile partners and create a tangible, positive impact in Malawi, contributing more widely to the betterment of the Malawian population.

\subsection{The context: Malawi's humanitarian drone corridor}

The United Nations Children Fund (UNICEF) Malawi has actively promoted drones in the humanitarian and development

\footnotetext{
${ }^{3}$ https://www.up4dream.com

${ }^{4} \mathrm{https}$ ://adda-malawi.org/
}

context. In partnership with the Government of Malawi, UNICEF Malawi was the first UNICEF office to establish a Humanitarian Drone Corridor and technology-friendly integrated airspace, where private entities, organizations, and academia can trial their drone technology and provide developmental solutions to the Malawi context. Ever since the UNICEF Malawi office tested a drone for the transport of dried blood spot (DBS) samples in 2016 and opened a drone corridor in Kasungu in 2017, the drone testing corridor has served as a sandbox enabling drone manufacturers, service companies, academia, and other drone service providers to test their services in a real-life humanitarian and development cooperation context.

The corridor is a dedicated airspace, with the center being at Kasungu Airport. Its size is almost $5000 \mathrm{~km}^{2}$, and it is a circular shape with a radius of $40 \mathrm{~km}$ (Figure 1).

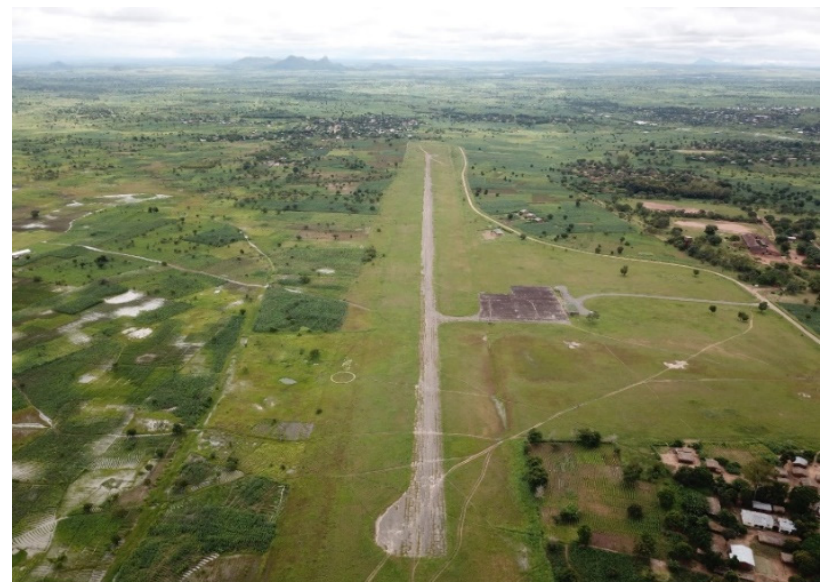

Figure 1. The district of Kasungu, with the UAV runaway located at the center of the corridor.

Several entities (academic and private) came to the corridor to test their prototypes or gather data for their AI (Artificial Intelligence) or other data analysis purposes. However, there has never been any large-scale mapping. Only a very tiny and not consistent area has been covered by drone mapping.

The Kasungu district ( $7000 \mathrm{~km}^{2}, \pm 500,000$ inhabitants) has two big rivers flowing, it has a district center (city) in it, has remote, hard-to-access villages, has a natural park, a small airfield, schools, health facilities, and many other items that are of interest from humanitarian survey/disaster preparedness perspective. Seasonally, it has flooding and drought problems that lead to malnutrition, lack of food, fresh water, disease (like Cholera) outbreaks, and other related issues. Additionally, like any other district in Malawi, it is exposed to malaria.

The key priorities of the corridor are the followings:

- Imagery: Generating and analyzing aerial images for development and humanitarian crises, including situation monitoring in emergencies and natural disasters, such as floods and earthquakes.

- Connectivity: Exploring the possibility for UAVs to extend Wi-Fi or cell phone signals across difficult-to-reach areas, particularly in emergencies or after a natural disaster.

- Transport: Delivery of small low weight supplies such as emergency medical supplies, vaccines, and samples for laboratory diagnosis, including HIV testing.

The UP4DREAM project focuses on the first key priority of the corridor (Imagery). As was already reported before, it has the aim of starting a capacity-building initiative, in line with other mapping mission in developing countries, focusing on the

\footnotetext{
${ }^{5} \mathrm{https}$ ://www.unicef.org/stories/humanitarian-drone-corridor-launchedmalawi
} 
realization and management of cartography at a large scale and high level of detail (using GIS - Geographic Information Systems) and on the generation of 3D products based on the UAV-acquired data.

The project is a genuinely innovative idea that, if embraced by local governments and programmatically implemented, can scale through various high-profile partners and create a tangible, positive impact in Malawi and, more widely, will contribute to the betterment of the Malawian population.

\section{PROJECT PHASES AND PERFORMED ACTIVITIES}

The one-year project followed mainly education and applied research principles based on technology transfer and capacitybuilding approaches.

From the 23rd of February to the 5th of March, a delegation from the Department of Architecture and Design (Filiberto Chiabrando and Alessio Calantropio) and the Department of Environment, Land, and Infrastructure Engineering (Andrea Lingua and Paolo Maschio) have been to Malawi for the first phase of the UP4DREAM project ${ }^{6}$. The experience was shared with colleagues from Amazon's disaster relief and response team to identify areas of collaboration with Amazon and Polytechnic in this project's framework.

The project comprises six primary phases: the test of procedure and practices, local partners' training, aerial data acquisition, processing with a photogrammetric approach, analysis of the processed data, result management, and sharing.

\subsection{Testing}

The first part of the test activities focused on data acquisition on a limited area of the corridor, using the up-to-date best available UAV technologies to define standards for extending the mapping operations to the whole corridor. Apart from the acquisition phase, conducting surveys on a limited portion of the territory provided enough data for running tests on the data processing aspect and set best practices for replicating the data acquisition to cover the whole corridor.

A part of the project activities was focused on testing data acquisition on a small portion of the corridor with the Swoop Aero platform. A two-day exercise has been performed in the Nsanje district, a flood-prone place in the south of the country that is and has been heavily affected by flooding in 2019 (Figure 2). Significant flooding events in that area are recurrent (every five years). The activities performed on the field also aim to provide support for emergency preparedness and response before the next disaster is expected.

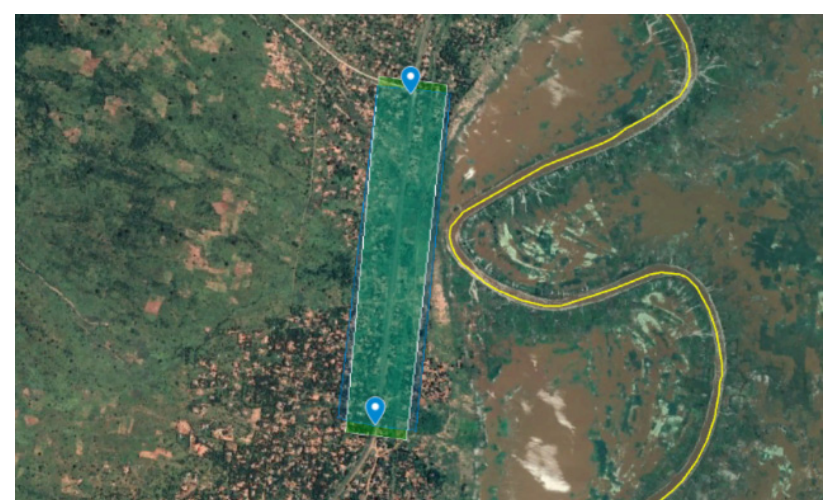

Figure 2. The area of the Nsanje district where the UAV imagery acquisition test has been performed.

${ }^{6} \mathrm{https} / / /$ www.isprs.org/news/newsletter/202002/61_UP4DREAM_first_report_updated.pdf
The company, who won a commercial tender and is currently working in the corridor on behalf of UNICEF Malawi, was expected to run organized and automated drone mapping missions (Figure 3) to acquire large amounts of aerial data, suitable for post-processing with photogrammetry software which will then be used for further analysis for various multiple applications. This step of the project was undertaken, always considering the Humanitarian UAV Code of Conduct ${ }^{7}$ and other inherent regulations and ethical dispositions.

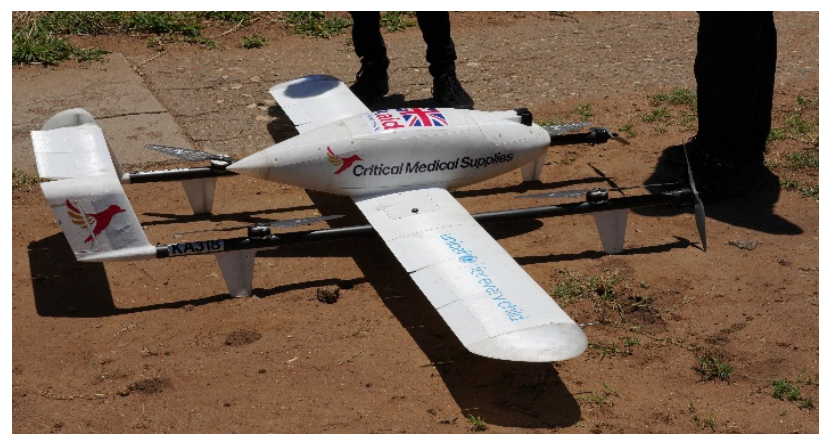

Figure 3. The VTOL UAV used by Swoop Aero in Nsanje.

The performed flight allowed the acquisition of images with a GSD (Ground Sample Distance) of $3 \mathrm{~cm}$ with $80 \%$ of longitudinal overlapping and $60 \%$ lateral overlapping.

Aside from the image acquisition and before the flight operations, several artificial markers were homogeneously distributed on the area. The markers were later used as GCPs or Check Points (CPs) in the performed photogrammetric processing to follow a rigorous metric approach.

The points were measured using GNSS (Global Navigation Satellite Systems) equipment using a Real-Time Kinematik (RTK) approach to obtain 3D coordinates with a precision of 2-3 cm (Figure 4).

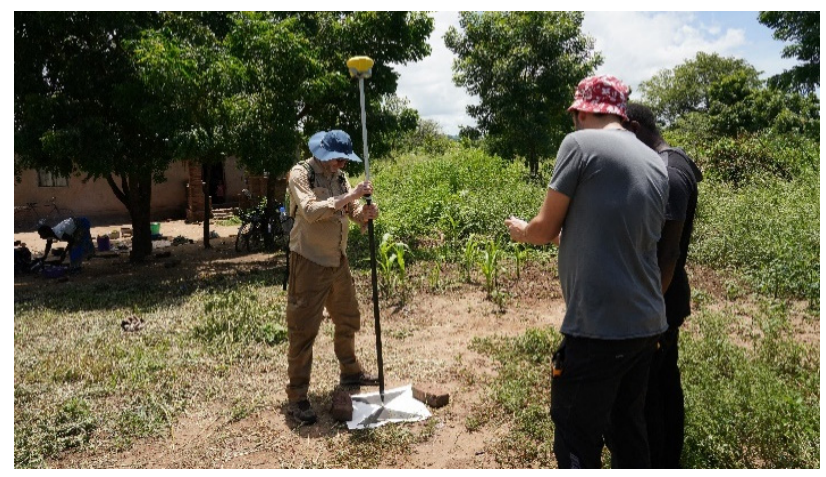

Figure 4. GCPs measurements in Nsanje district.

\subsection{Training}

A further objective of UP4DREAM was related to developing future drone operators' technical training activities with a Capacity Building Approach, using in-situ education actions. The target of this educational experience has been students of the African Drone and Data Academy, researchers and professors of local universities (Lilongwe University of Agriculture and Natural Resources, and Mzuzu University), other institutions and organizations such as COOPI and the DODMA (Department of Disaster Management Affairs - Malawi) and companies that are currently working on the corridor to gather UAV imagery data (Swoop Aero).

\footnotetext{
${ }^{7}$ https://uavcode.org/
} 
The training phase's goal was to ensure that the local partners can continue mapping operations without external specialists coming from outside the country in the most simple and standardized way.

The first activity has been carried out with the ADDA students (The African Drone and Data Academy). In the academy, the overall educational curriculum covered aspects related to the UAV data acquisition, Georeferencing strategies using GNSS data, Photogrammetric data processing, large data management, data storage, and visualization using GIS software and tools.

During the training session, a large part was dedicated to the use of the Metashape software for drone imagery processing, setting up of ground control points to enhance the accuracy levels of the acquired drone imagery, as well as support ADDA with the structural development of their academic curricula, most especially around drone imagery acquisition/processing (Figure $5)$.

Activities have also been carried outside the class, with the acquisition of GCPs, the flight plan design, and execution, both with fixed-wing (Figure 6) and multirotor UAV.

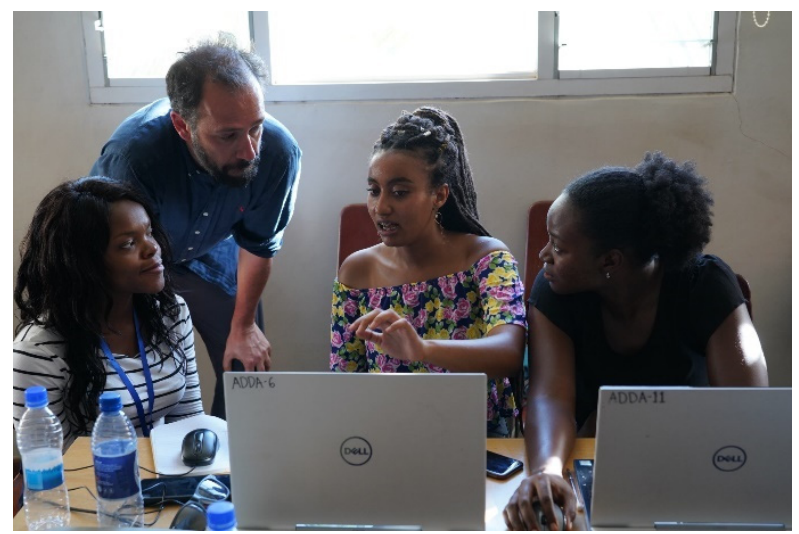

Figure 5. Training session during the ADDA workshop on the use of photogrammetry software.

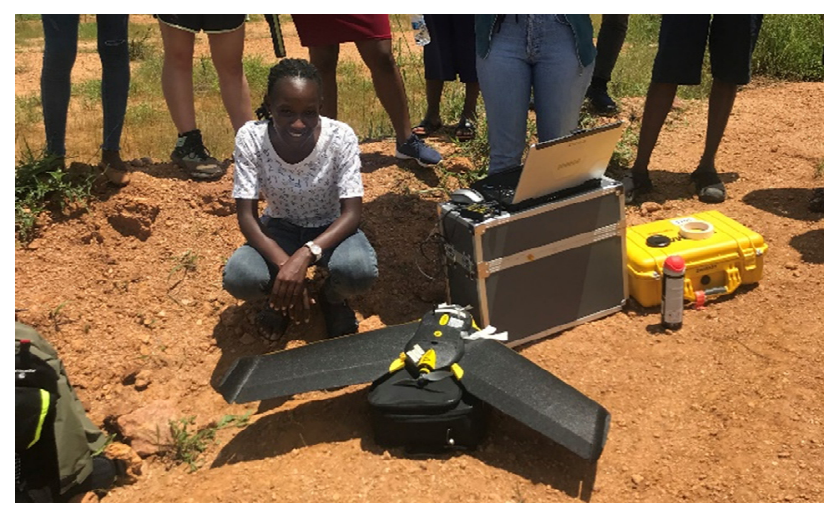

Figure 6. Training session during the ADDA workshop on the use of UAV.

A second capacity building workshop has been organized with partners from the Academia (Malawi University of Science and Technology, Lilongwe University of Agriculture and Natural Resources, MZUZU University) as well as four colleagues from DODMA (Department of Disaster Management Affairs), COOPI (Cooperazione Internazionale) and with the UNICEF staff (Figure 7).

The outcome of the capacity-building exercise was entirely satisfactory as it was a good learning experience for all parties involved in the activity. Colleagues from academia, ADDA, DODMA and expressed satisfaction with the exercise and even requested more similar training in the nearest future.

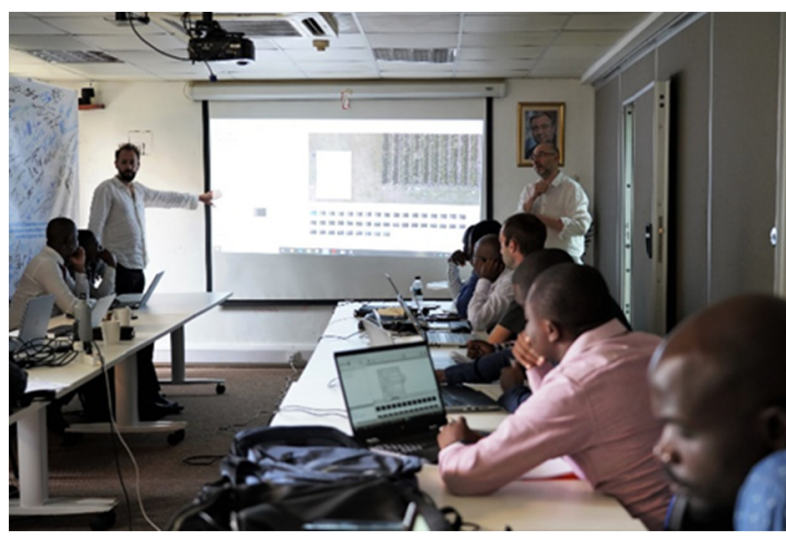

Figure 7. Meeting with representatives of the local institutions, UNICEF, DODMA, COPI, and the partner universities.

\subsection{Data acquisition}

This phase was designed initially to aim at a large-scale data acquisition (drone mapping) mission, where the whole territory of the corridor will be clustered and covered to gather consistent aerial data. The local partners were expected to run organized and automated drone mapping missions in order to acquire large amounts of aerial data, suitable for post-processing with photogrammetry software to be later used for further analysis for various multiple applications, such as flood modeling, mosquito breeding site identification, watershed monitoring, and similar. Due to the outbreak of the COVID-19 Crisis, it was unfortunately impossible to fully achieve this result, as operation with the partners on the field was interrupted. However, the acquisition phase was supposed to constitute the practical module of the training phase, in which it should have been possible to apply what previously learned. Nevertheless, partners have been trained on designing flights according to the photogrammetric principle (GSD, overlapping, and the validation of a reasonable metric accuracy of the achieved products via GCPs and CPs measured with GNSS equipment). Concerning this future possibility, and thanks to the ISPRS support, Polytechnic University of Turin donated two GNSS survey equipment units to UNICEF Malawi.

\subsection{Data processing}

Processing of the data has been performed on a crowd-sourced basis; thanks to the possibility of deploying 10 Agisoft Metashape licenses, data processing has been performed in a decentralized format; the outcomes of this process will be accessible for free (under request) by academia, international organizations, donors, and local Malawian authorities. The photogrammetric processing was performed to obtain traditional orthoimages and 3D products such as DSM (Digital Surface Models) and 3D meshes to improve the country's understanding. Agisoft Metashape issued one-year software licenses for continuing with the activities of the project. On the other hand, Amazon donated three units of their world-class ruggedized supercomputer (Amazon Snowball edge) to UNICEF Malawi. The device will be used to process sizeable drone imagery, store the imagery data, and share the processed file(s) to a hosted cloud server. This, in turn, will support UNICEF's programmatic efforts, most especially around the flood modeling project and the planned mosquito breeding sites mapping.

\subsection{Data sharing}

Data sharing has been conducted under open licenses and dedicated spatial geodatabase to make accessible the gathered 
data to all the potential users, the ISPRS community, the academic and research world, Non-Governative Organizations, International Organizations, Funders, and local authorities. The original idea was to involve the international community of ISPRS for data processing to cut off related costs and provide the scientific community with a large dataset for several purposes oriented to education and research activities. However, as only small acquisition tests were performed due to COVID-19 related issues, it was possible to provide a pilot study experience covered internally by the project member.

\subsection{Data management and analysis}

The last part of the project will focus on managing/analyzing the processed data, involving when relevant and when needed the ISPRS international scientific community. The study will cover several research aspects and will be used for different purposes: the realization of maps at a large scale of crops (precision farming), monitoring of the mosquito's reproduction sites, monitoring of rivers and body waters, generation of flooding/drought models, tracking of deforestation processes, water point detection any other kind of analysis related to the infrastructures located on the analyzed area (households, roads, schools, health facilities, markets, or any other crucial places that are essential for agriculture/emergency preparedness/nutrition/other).

Data analysis will focus on any other parameters functional for agriculture applications, emergency response, and for the evaluation of urban regeneration/reorganization scenarios.

This part will be covered by multiple different entities with scientific/research/developmental interests in collaborating with the Malawian Government. Some analyses were already performed on two different areas and are reported in the next section.

\section{ORGANIZATION OF A SPATIAL GEODATABASE FOR RISK-RELATED ANALYSIS}

After a deep analysis of the available data among the geoportals in Malawi, some problems related to data consistency and transparency were founded. Moreover, different issues relating to the data accountability in GIS-based analysis when dealing with natural hazards and disaster assessments were noticed. According to those issues, the research reported hereafter aims to provide an innovative approach to dealing with data collection and emergency preparedness. The introduction of UAV imagery and the support of artificial intelligence algorithms into territorial analysis bring a crucial contribution in identifying buildings' footprints and infrastructures, particularly useful after hazardous natural events.

This section aims to describe the phases of the approach undertaken to organize a geodatabase. This geodatabase can be used in future emergency and preparedness activities.

In order to apply the proposed methodology, two areas in south Malawi were selected. The first analysis has been carried out in the Nsanje district; here, an assessment of the georeferentiation accuracy that UAV orthoimages can achieve has been performed. This accuracy is essential in the ordinary mapping of the built environment and cartographic implementations, foremost in emergency preparedness.

Besides, the second analysis consists in the gathering of multitemporal satellite images $(2013,2015$, and 2019) that takes into account previous hazardous events and the overlapping of

\footnotetext{
${ }^{8}$ https://download.geofabrik.de/africa/malawi.html

${ }^{9} \mathrm{https}: / /$ malawi.4p2c.org/portal/apps/webappviewer/index.html?id=bb5 $820 \mathrm{e} 275 \mathrm{ab} 4 \mathrm{~d} 44 \mathrm{ab} 2 \mathrm{f} 9 \mathrm{c} 4 \mathrm{bec} 9 \mathrm{f} 2 \mathrm{~b} 1 \mathrm{e}$

${ }^{10} \mathrm{https}$ //data.humdata.org/dataset/floods-malawi-2019
}

available event data (like the water extension shapefile) provided by UNICEF, Netherlands Red Cross, OSM (Open Street Map) and eventually, the additional set of UAV data that has been already collected.

Because of the multiplicity of sources (OSM ${ }^{8}$; UNICEF 20199; Netherlands Red Cross 2019 ${ }^{10}$; COOPI 2018 Copernicus $^{12}$; EO Browser Sentinel data ${ }^{13}$ ), a new comprehensive Geodatabase has been created using a Geographic Information System software (ArcGIS Pro) to provide a clear and comprehensive set of data (Figure 8), easily accessible. In order to correctly implement the GIS, the followed steps have been undertaken:

- The employment of the reference system, EPSG:32736 WGS84/UTM zone 36S;

- The creation of a feature dataset, within the new file geodatabase, containing all the primary vector data:

- The buildings and infrastructures Open Street Map vectors;

- The water and waterways vectors from Open Street Map;

- The Netherlands Red Cross flood extent data that combined 2019 Cyclone Idai flood extent data from march 7,10 , and $14^{\text {th }}$;

- The building/shaping/constructing of two different mosaic dataset:

- The first one is containing the UAV raster data (orthoimages and DSM) containing the Nsanje achieved products;

- The second one is collecting a series of satellite raster data (from Landsat 8) over the Bangula district to explore past hazardous events (2013, 2015, and 2019) and further explore the water extent.

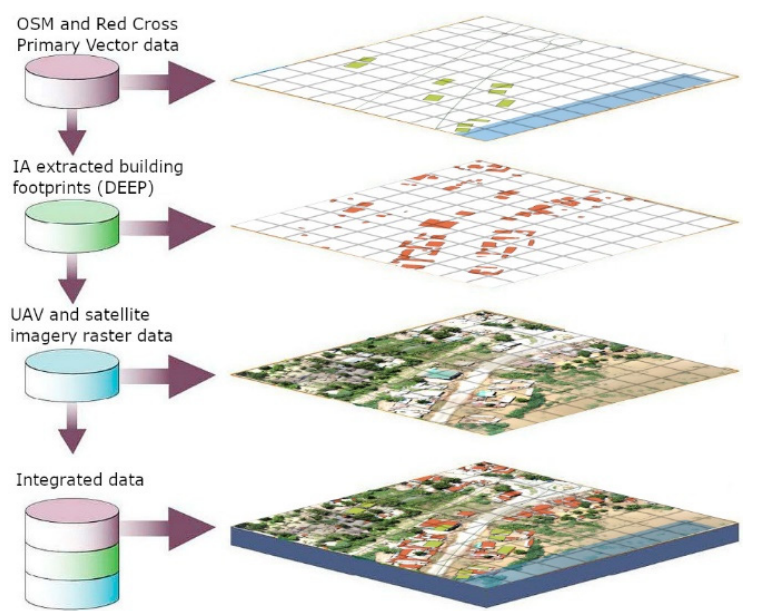

Figure 8. Process map that summarizes the different GIS layers.

Furthermore, how it is reported in the following sections, specific analyses have been carried out in the two selected districts.

\subsection{Nsanje}

In the analysis performed over the district of Nsanje, the OSM data for buildings and infrastructures has been overlapped along with Netherlands Red Cross flood extent data (March 2019) to achieve a first estimation of the flooded, hence affected asset of buildings and infrastructures (Figure 9).

\footnotetext{
${ }^{11}$ https://gis-malawi.com

${ }^{12} \mathrm{https} / / /$ emergency.copernicus.eu/mapping/ems/copernicus-ems monitors-floods-malawi

${ }^{13} \mathrm{https}$ ://apps.sentinel-hub.com/eo-browser
} 


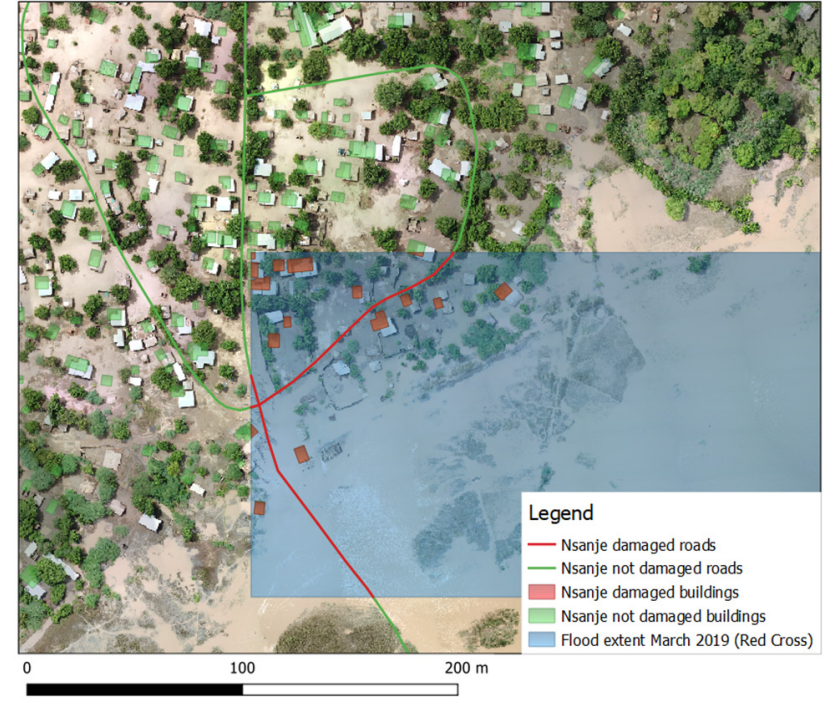

Figure 9. UAV orthophoto of Nsanje (UNICEF 2019); superimposed the flood extent layer (blue) with the affected buildings and roads (in red) after the 2019 Cyclone Idai flooding.

«Flood impact mappings» indeed «[...] requires the availability of reference geo-information layers and the crisis/disaster flood extent mapping to support semi-automatic identification of the potentially affected infrastructures and suitable post-event optical imagery at an adequate level of detail to estimate a potential damage grade» as stated in the IWG-SEM Emergency Mapping Guidelines (IWG-SEM, 2014). Following this methodology, a first classification of the potential damage level on the infrastructures and buildings system has been performed. These two vector data have indeed been overlapped along with the Netherlands Red Cross water extent and classified using the following values: 1- Flooded roads/buildings, as entirely within the water extent data; 2- Potentially affected roads/buildings, as even partially intersected with the flood data; 3- Potentially practicable roads and potentially safe buildings, as a result of no intersection between the flood extent and the vector layers. This sort of analysis, however, presents weaknesses of consistency with the actual damage. A more accurate grade of buildings' potential damage can be achieved thanks to the UAV imagery that the Polytechnic team has collected during the 2020 UP4DREAM expedition.

Thanks to UAV data, more precise information relating to the built environment's current state and the infrastructural system usually visible from the satellite data can be identifiable.

Moreover, as the role of Artificial Intelligence already proved to be effective in combination with UAV data in humanitarian actions (Oren \& Verity, 2020), an innovative approach has experimented through the extraction of UAV buildings footprints using a building segmentation model implemented in the DEEP (Digital Engine for Emergency Photo-analysis) neural network algorithm (Calantropio, et al., 2021) over the available Nsanje orthophoto (Figure 10).

This operation allowed two prominent acknowledgments: the recognition of an erroneous georeferencing of the existing (not recently updated) buildings' footprint data, which could be improved through complete finalization of the UAV imagery dataset that could be later implemented in the ordinary territorial planning and assessment, and for more precise identification of the event impacted buildings, particularly useful in the emergency preparedness.

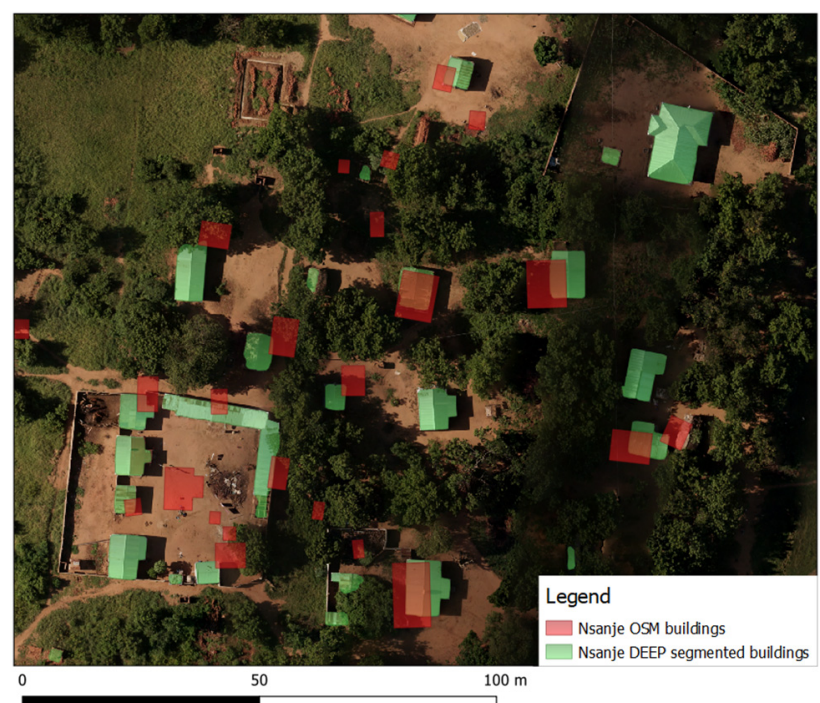

Figure 10. UAV orthophoto of Nsanje (UP4DREAM 2020); superimposed the building footprints generated by AI techniques (in green) and retrieved from OpenStreetMap (in red). It is possible to observe how the OSM data is incomplete and inaccurate compared to the UAV survey's vector data.

\subsection{Bangula}

A similar analysis has been carried out in the Bangula district. Firstly the creation of a multitemporal satellite images dataset of the area: this includes 2013, 2015, and 2019 images (EMS Copernicus and EO Browser Sentinel data), referring to yearlyprevious natural hazards that affected the country in the past years, to show the evolution and extension of flooded areas has been achieved in order to allow a more comprehensive understanding of the frequency of natural hazards in the area and the earliest cognition of the damage level, thanks to the water extents visible from the infrared satellite images. As it is possible to observe in the following figure 11 and figure 12, UAV data can provide more accurate and trustworthy information (at the scale of the buildings) compared to satellite-based vector information (mainly aimed at a territorial scale assessment).

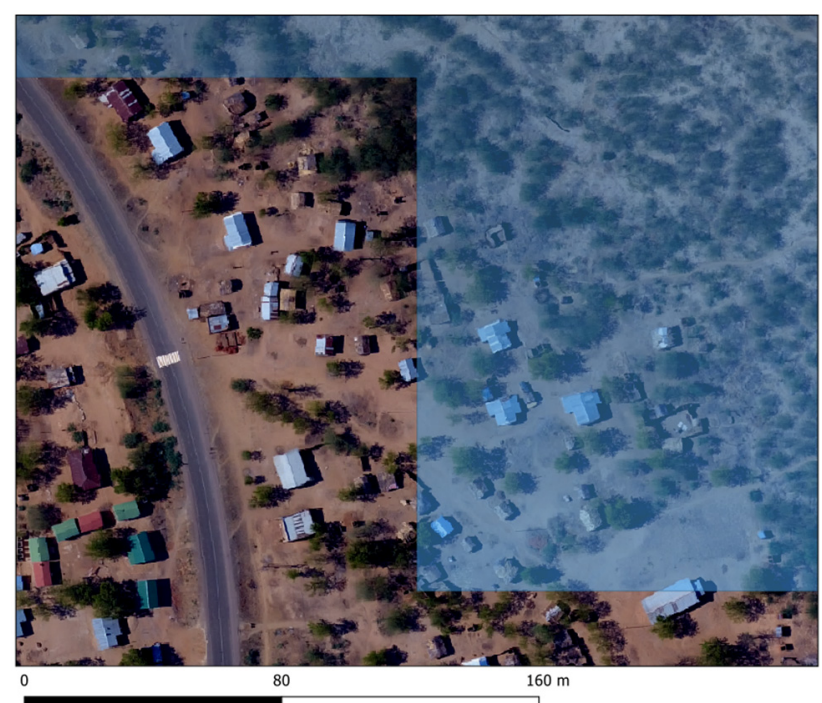

Figure 11. pre-event UAV orthophoto of Bangula (COOPI 2018); superimposed the flood extent of march 2019

(Netherlands Red Cross). 


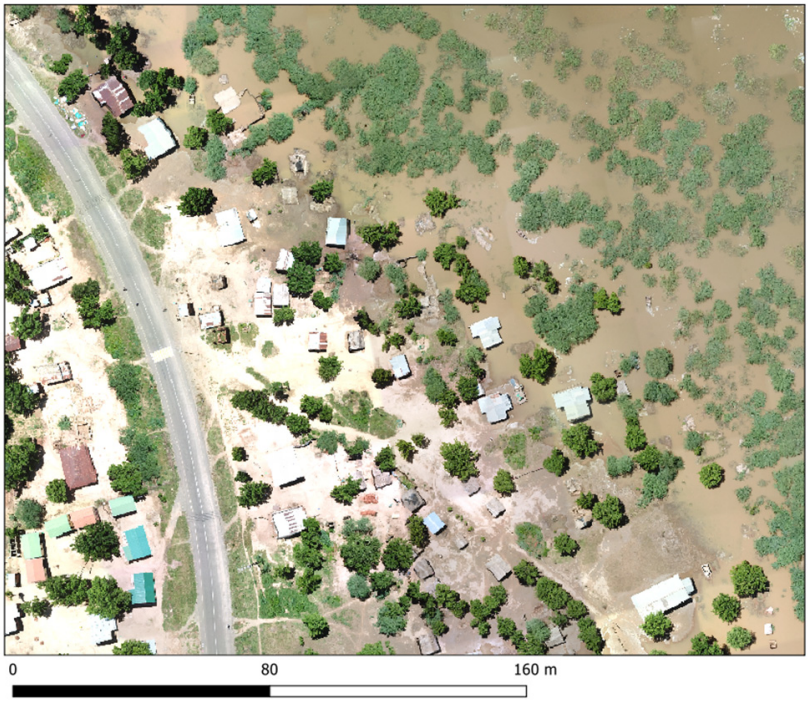

Figure 12. post-event UAV orthophoto of Bangula (UNICEF 2019).

According to the achieved results, it is possible to state that the introduction of UAV imagery does not presume as a substitute to satellite imagery. Instead, it provides a complimentary support towards a more accurate definition of the urban environment, specifically useful for buildings and residential buildings location when emergencies occur. This closer level of detail becomes effective in ordinary mapping, mainly for cartographic purposes, and key when dealing with extraordinary situations, such as emergency preparedness and post-event emergency assessment. Taking into consideration the goals and challenges stated in the Malawi Country Strategic Plan 2019-2023 (World Food Programme, 2019), UAV imagery involvement in ordinary and extraordinary mapping could also foster land use analysis, so to have a better acknowledgment not only on the flooded land but also how the loss of primary resources, such as agricultural fields. Indeed, a detailed land-use drone mapping and consequent analysis could lead to identifying potential safe spots, turning points in emergencies, such as that of Cyclone Idai in 2019, for people gathering or even food, water, and medicaments distribution.

\section{PROJECT'S OUTCOMES AND FUTURE PERSPECTIVES}

Apart from updating the aerial maps of Malawi, the primary outcomes of the project were the development of capacity building activities and the creation of a comprehensive geodatabase for data visualization and management of UAV acquired data, encouraging not only the use of open data policy but also enhancing early warning and improve emergency preparedness by increasing the impact of the humanitarian effort. More in detail, the essential outcomes of the project and the related future perspectives are the following.

\subsection{Set the basis for a large-scale UAV mapping opportunity}

So far, the number of areas mapped by drones in Africa is minimal. The project's main aim was to provide a straightforward methodology and a set of tools to reach an up-to-date aerial imagery dataset of the corridor to help Malawian people map out disease and disease risk across the country. Mapping a territory expands its knowledge and supports the development of the population's resilience, offering a powerful tool that, linked to GIS, will allow precise spatial analysis in natural disaster or disease outbreak situations. This project contributed to the first steps towards mapping Malawi and its vulnerable areas for better emergency preparedness and improved socio-economic development. Our local partners will be involved in continuing the mapping experience to acquire relevant aerial data, which will then be shared with the ISPRS community.

\subsection{Enhance early warning and improve emergency} preparedness via GIS tools and platforms

Drones can also be used as tools to predict and assess the situation before a disaster, rather than just as a response too ${ }^{14}$. Getting high-resolution drone-acquired data and creating vulnerability maps would increase authorities' capacity to set up efficient early warning systems and improve emergency preparedness. Understanding the risks of the territory is the first step towards increasing the population's resilience; for the reasons mentioned above, the collected data have been implemented in a spatial geodatabase that will be made available to the Malawian Government. The Government and non-governmental institutions can use this geodatabase for risk assessment and planning activities, such as land tenure and environmental monitoring. Disaster risk reduction, response, and recovery operations require timely and reliable data to make informed decisions ${ }^{15}$. One of this project's possible prosecutions will be to identify and implement policy and coordination solutions and technical and data analysis solutions to reduce data dispersion among GIS platforms and increase our partners' humanitarian efforts in Malawi.

Finally, the project partners are exploring, as a possibility, ways to support the Malawi Government in developing a national GIS Platform and analyze the use of geomatics for automated \& precision agriculture to improve crop yields). Adopting an open data policy on all these steps will ensure the involvement of a worldwide research community.

\subsection{Education outreach and scientific research activities}

A few future collaboration areas were outlined as future steps: the researcher's exchange is expected, and colleagues from academia indicated an interest in possible exchange programs with the Polytechnic University of Turin. Therefore, MoU with interested partners will be signed to explore the possibility of staff exchange and publishing joint academic papers in international journals.

Plans include the organization of one-week training activities; the authors explored having another capacity-building exercise online or on-site. Polytechnic is also willing to support ADDA in developing their academic curricula regarding drone imagery acquisition, processing \& use. Various collaborations will also be investigated with Virginia Tech (the academic UNICEF partner in the ADDA project). The organization of ad-hoc on-site training and online training sessions in the Education field (Photogrammetry/GIS) will be run in collaboration with the Lilongwe University of Agriculture and Natural Resources and Mzuzu University.

One of the ultimate results of this joint effort will likely be a recommendation guideline on further developing in-country drone mapping operations. The lesson learned will serve as standards and best practices for establishing sustainable drone project implementers and donors' sustainable procedures.

\footnotetext{
${ }^{14}$ https://blogs.unicef.org/blog/flying-drone-malawi-my-firstemergency-deployment/
}

\footnotetext{
${ }^{15}$ https://werobotics.org/aidrobotics/
} 


\section{CONCLUSIONS}

Geomatics and Remote Sensing technology are crucial, especially in developing countries that cannot usually rely on well-structured emergency and preparedness response tools. One of the most important aspects is that UAV data's interoperability with satellite images from different sources allows for a comprehensive, multiscale analysis of natural hazards and reduces the gap of information that usually affects developing countries' data sets. UAV imagery data indeed proved to be an affordable and reliable support in case of emergency for helping Government and stakeholders arrange emergency preparedness plans. The capacity-building approach on which UP4DREAM is based ensures social good by empowering local communities through professional training and self-consultancy rather than external intervention as a critical solution to improve resilience in developing countries contexts. Moreover, the capacitybuilding approach betters the area's resilience, enhancing the preparedness for possible future events. In this scenario, continuous development of projects for training the local communities needs to be followed to create local capacity devoted to improving education activities at different levels.

The project is still under development, and the new update could be founded at www.up4dream.com.

\section{ACKNOWLEDGEMENTS}

The authors would like to thank ISPRS for the economic support that made this initiative possible. Thanks to the United Nations Children Fund - UNICEF Malawi for co-funding the project and supporting us, especially in the project's initial phases. Thanks to Agisoft LLC in the person of Liubov Rozhkova for making available 10 Agisoft Metashape Pro licenses for the partners of this project during the whole life of the project. Many thanks to the other colleagues of this scientific initiative: Mavuto Denis Tembo, Rochelle H. Holm, Brighton Austin Chunga, Joshua Mchenga of the Mzuzu University, and Daud Jones Kachamba of the Lilongwe University of Agriculture and Natural Resources. The authors would like to thanks also Emmanuel Chinkaka and Dickson Mbeya (Malawi University of Science and Technology), Jonathan Chambers (COOPI), James Devine and Cayce Pack (Amazon), Morgan Mayani, Innocent Manyera, and Lyford Chipukunya (Department of Disaster Management Affairs Malawi), Brian Kamamia and Robert Hedman (African Drone and Data Academy), and Matthew Zafir and Sabrina Ravail (Swoop Aero).

\section{REFERENCES}

Back to the Future: Drones in Humanitarian Action - WeRobotics Blog. (2019). Retrieved from https://blog.werobotics.org/2019/11/12/back-to-the-futuredrones-in-humanitarian-action/

Boccardo, P., Chiabrando, F., Dutto, F., Tonolo, F. G., \& Lingua, A. (2015). UAV deployment exercise for mapping purposes: Evaluation of emergency response applications. Sensors, 15(7), 15717-15737.

Bonte-Grapentin, M., Meier, P., \& Saito, K. (2017). Lessons From Mapping Geeks: How Aerial Technology is Helping Pacific Island Countries Recover From Natural Disasters. World Bank Blogs. Retrieved from https://blogs.worldbank.org/eastasiapacific/lessons-mappinggeeks-how-aerial-technology-helping-pacific-island-countriesrecover-natural
Bravo, R., \& Leiras, A. (2015). Literature review of the application of UAVs in humanitarian relief. Proceedings of the XXXV Encontro Nacional de Engenharia de Producao, Fortaleza, Brazil, 13-16.

Calantropio, A., Chiabrando, F., Codastefano, M., Bourke, E. (2021). Deep Learning for automatic building damage assessment: application in post-disaster scenarios using UAV Data. ISPRS Ann. Photogramm. Remote Sens. Spatial Inf. Sci., (on press).

Hardy, A., Makame, M., Cross, D., Majambere, S., \& Msellem, M. (2017). Using low-cost drones to map malaria vector habitats. Parasites \& vectors, 10(1), 1-13.

International Working Group on Satellite-based Emergency Mapping (IWG-SEM) VA (2014). Emergency mapping guidelines. Working Paper (v1.0). Retrieved from http://www.un-

spider.org/sites/default/files/IWG_SEM_EmergencyMappingG uidelines_A4_v1_March2014.pdf

Koeva, M., Muneza, M., Gevaert, C., Gerke, M., \& Nex, F. (2018). Using UAVs for map creation and updating. A case study in Rwanda. Survey review, 50(361), 312-325.

Lalrochunga, D., Parida, A., \& Choudhury, S. (2020). Sustainability of UAVs in developing countries: Prospects and challenges. Journal of Discrete Mathematical Sciences and Cryptography, 23(1), 237-248.

Meier, P. (2018). Empowering Youths in Fiji to Explore their Islands with Aerial and Marine Robotics | iRevolutions. Retrieved from https://irevolutions.org/2018/02/22/aerialmarine-robotics-fiji/

Mugala, S., Okello, D., \& Serugunda, J. (2020). Unmanned aerial vehicles: Opportunities for developing countries and challenges. In 2020 IST-Africa Conference (IST-Africa) 1-10.

Oren, C., Verity, A. (2020). Artificial Intelligence (AI) Applied to Unmanned Aerial Vehicles (UAVs) and its impact on Humanitarian Action, Digital Humanitarian Network.

Strickland, E. (2018). Drone Delivery Becomes a Reality in Remote Pacific Islands - IEEE Spectrum. Retrieved from https://spectrum.ieee.org/the-human-

os/biomedical/devices/drone-delivery-becomes-a-reality-inremote-pacific-islands

Triche, R. M., Greve, A. E., \& Dubin, S. J. (2020). UAVs and Their Role in the Health Supply Chain: A Case Study from Malawi. In 2020 International Conference on Unmanned Aircraft Systems (ICUAS) 1241-1248.

UNICEF Kazakhstan. (2019). UNICEF and the Government of Kazakhstan Begin Test Flights for Emergency Response | UNICEF Office of Innovation. Retrieved from https://www.unicef.org/innovation/stories/unicef-andgovernment-kazakhstan-begin-test-flights-emergency-response

World Food Programme (2019) Malawi Country strategic plan (2019-2023) Retrieved from https://www.wfp.org/operations/mw01-malawi-countrystrategic-plan-2019-2023 